DOI: 10.12731/2658-4034-2020-6-17-30

УДК 159.955.1:159.9.018.5:681'33

\title{
ЯЗЫКОВЫЕ ПРЕДСТАВЛЕНИЯ КАК ФОРМА СОЦИАЛЬНОГО ЗНАНИЯ
}

Разумова Л.В.

Цель. Статья посвящена уточнению характера языковых знаний в системе социального знания. Социальное представление (репрезентация) - сложная когнитивная структура. Как сочиальная форма знания сочииальное представление служтт для интерпретации социальной действительности. Оно позволяет понять и подвергнуть анализу регулирующее действие сочиальной системы на когнитивную область сочиальной группь, индивида. Автор ставит иелью уточнить основные характеристики языкового представления (языковой репрезентащии) и его структуру как формы сочииального знания. Актуальность статьи определяется, с одной сторонь, возросшим интересом к когнитивным разработкам, способных раскрыть сложные механизмы категоризации человеческих знаний. С другой стороны, речь идет о попьтке автора применить психологическое понятие представления для уточнения психосоциильных характеристик языковых знаний, в частности - представлений о языковой норме как одной из форм сочиального знания.

Научная новизна исследования заключается в соотнесении социиально-психологической и языковой основ языковой репрезентации.

Теоретическая и практическая значимость работы состоит в комплексном анализе взаимодействия социальной среды, функииональной системы языка с его внутренней структурой на примере изучения репрезентации языковой нормы бельгийского и квебекского вариантов франиузского языка.

Материалом для исследования послужили языковые представления носителей языка о языковой норме территориальных вариантах франиузского языка Бельгии и Квебека, представленных 
в бельгийских и франщузских грамматиках XVI-XIX вв., квебекских лексикографических работах XVIII - начала ХХ столетий, в исторических свидетельствах о языке.

Результаты исследования. Инструментарий социальной психологии, основной единицей которой вылтупает социальная репрезентация, позволил существенно расширить представление о норме как сложной когнитивной структуре, опирающейся не только на разрабатываемое в обществе научное знание, но и на знание естественное, опьтное, которому свойственно неограниченное число инференций, следований, что позволяет установить неограниченное число связей между наблюдаемыми предметами. Соединение научного и опьтного знания, сочиального и индивидуального определяют амбивалентньй, рационально-оценочный, с одной стороны, и социально-индивидуальный характер нормы, с другой. Языковая норма как один из типов сочиальной нормы формируется в прочессе взаимодействия нескольких сочиильных групп, определяющих свое отночение, в том числе и идентификационное, к языку (языковой форме).

Ключевые слова: сочиальные представления; языковые представления; научная и житейсткая формы знания; социальное и индивидуальное знание; смыслообразующая и организующая функиии представления; языковая норма.

\section{LANGUAGE REPRESENTATIONS AS A FORM OF SOCIAL KNOWLEDGE}

\section{Razumova L.V.}

The article is devoted to clarifying the nature of language knowledge in the system of social knowledge. Social representation is a complex cognitive structure. As a social form of knowledge of social representation is used for the interpretation of social reality. It allows us to understand and analyze the regulatory effect of the social system on the cognitive domain of a social group, an individual. The author aims to clarify the main characteristics of language representation and its structure as a 
form of social knowledge. The relevance of the article is determined, on the one hand, by the increased interest in cognitive developments that can reveal complex mechanisms of categorization of human knowledge. On the other hand, we are talking about the author's attempt to apply the psychological concept of representation to clarify the psychosocial characteristics of language knowledge, in particular, ideas about the language norm as a form of social knowledge.

The scientific novelty of the study lies in the correlation of the socio-psychological and linguistic foundations of linguistic representation.

The theoretical and practical significance of the work consists in a comprehensive analysis of the interaction of the social environment, the functional system of the language with its internal structure by the example of studying the representation of the language norm of the Belgian and Quebec versions of the French language.

The material for the study was the linguistic representations of native speakers about the language norm of the territorial variants of the French language of Belgium and Quebec, presented in Belgian and French grammars of the XVI-XIX centuries, Quebec lexicographic works of the $X V I I I$ - early XX centuries, in historical evidence about the language.

The results of the study. The tools of social psychology, the main unit of which is social representation, allowed us to significantly expand the idea of the norm as a complex cognitive structure, based not only on the scientific knowledge developed in society, but also on natural, experimental knowledge, which is characterized by an unlimited number of inferences, followers, which allows us to establish an unlimited number of connections between the observed objects. The combination of scientific and experimental knowledge, social and individual, determines the ambivalent, rational-evaluative, on the one hand, and the socio-individual nature of the norm, on the other. The language norm as one of the types of social norm is formed in the process of interaction of several social groups that determine their attitude, including identification, to the language (language form).

Keywords: social representations; language representations; scientific and everyday forms of knowledge; social and individual knowledge; meaning-forming and organizing functions of representation; language norm. 


\section{Актуальность исследования}

Публикации последних лет свидетельствуют, что основными проблемами современной когнитивной науки выступают вопросы определения человеческих знаний, их типов, их представленности в сознании индивида и группы, а также их усвоения и использования [Фаликман, 2014; Тагард, 2014; Lakoff G.,1990] .

Сегодня для когнитивистского направления характерно, с одной стороны, обращение к анализу сложных ментальных процессов, раскрывающих не только свойства и структуры человеческой психики, но и включенность человека в процесс конструирования и усвоения знания, создаваемого им самими и социальной группой. С другой стороны, современные когнитивные исследования определяются использованием междисциплинарного подхода ввиду привлечения для анализа многочисленных и разнородных предметов исследования, принадлежащих ранее четко отграничиваемым научным дисциплинам (психологии, языку, социологии, экономике и пр.) и которые сегодня рассматриваются все чаще в парадигме сложности и взаимосвязанности. Когнитивная лингвистика, социальная лингвистика - лишь несколько примеров такой междисциплинарной интеграции. Они способны также включать в разной пропорции арсенал средств, методов и понятий других дисциплин, например, социальной психологии. К последним относим привлечение для анализа понятия представления.

\section{Результаты исследования}

Представление («воображение» [Рубинштейн, 2002], «мысленные образы», «внутренняя картина» [Солсо, 2002]) - один из важных способов организации знаний в психике человека. Оно включено во все основные виды человеческой деятельности в качестве активного когнитивного компонента. Понятие представления выступает одним из центральных понятий психологии и восходит к понятию «коллективные представления», введенного в научный обиход Э. Дюркгеймом. Дальнейшую разработку понятие «представление», «коллективное представление» получило в работах 
представителей французской социальной психологии - ее основателя С. Московичи и его последователей Д. Жоделэ, В. Дуаз, П. Молине [Jodelet, 2015; Moliner, Guimelli, 2015; Doise, 1990] и др. Под социальным представлением принято понимать особый способ конструирования знания, разделяемого в рамках определенной социальной группы [Moscovici, 1990]. В рамках французской школы социальной психологии подчеркивается, что понятие социальной репрезентации позволяет лучше понять связь человека, социальной группы и общества.

Социальный характер коллективно конструируемой формы знания обнаруживает в исторической перспективе и представление о языковой норме, в частности - языковой норме французского языка как на территории самой Франции, так и в ее пространственных вариантах в Бельгии и Квебеке. Представления о языковых нормах данных пространственных вариантах французского языка конструируется в процессе контактирования различных групп говорящих и использования ими различных языковых форм: латинского, французского, многих локальных форм речи.

К основным условиям, необходимым для выработки социальных представлений (репрезентаций) относится, прежде всего, сложность наблюдаемого социального объекта [Moliner, Guimelli, 2015].

Бельгийский и квебекский варианты французского языка выявляют сложный и динамично меняющийся характер репрезентаций языковых норм, функционирующих на данных территориях.

Так, в своем историческом развитии бельгийский вариант французского языка предстает как вариант, существующий в условиях постоянной диглоссии и полилингвизма. Он конструируется на основе множественных письменных и устных языковых форм, языковые нормы которых выступают в истории как опорные друг для друга и одновременно как альтернативные языковые нормы. При этом, письменная и устная формы обнаруживают различные «предпочтения» в выборе своих опорных языковых норм. Обобщение исторических вариантов взаимодействия различных языковых норм на территории Бельгии приводятся в таблице № 1 . 
Таблицуа 1.

Взаимодействия языковых норм на территории Бельгии в I-XVI вв. по Л. Разумовой (Разумова, 2014а: 121-122)

\begin{tabular}{|c|c|c|c|}
\hline Дата & $\begin{array}{l}\text { Лингвистиче- } \\
\text { ские и экстра- } \\
\text { лингвистиче- } \\
\text { ские сведения } \\
\end{array}$ & Устная речь & Письменная речь \\
\hline I-III вв. & $\begin{array}{l}\text { Романизация } \\
\text { Белгики }\end{array}$ & $\begin{array}{l}\text { Кельтско-франк- } \\
\text { ское двуязычие }\end{array}$ & $\begin{array}{l}\text { Латинский язык с единой языко- } \\
\text { вой нормой }\end{array}$ \\
\hline IV-VIII вв. & $\begin{array}{l}\text { Завоевание } \\
\text { Белгики фран- } \\
\text { ками и начало } \\
\text { дифференци- } \\
\text { ации местных } \\
\text { галлороман- } \\
\text { ских и герман- } \\
\text { ских } \\
\text { форм речи } \\
\text { (диалектов) }\end{array}$ & $\begin{array}{l}\text { Кельтско-франк- } \\
\text { ское-галлоро- } \\
\text { манское многоя- } \\
\text { зычие и переход } \\
\text { к неустойчивой } \\
\text { франкско-гал- } \\
\text { лороманской } \\
\text { диглоссной си- } \\
\text { туации }\end{array}$ & $\begin{array}{l}\text { Полиномичный латинский язык с } \\
\text { альтернативными эволютивными } \\
\text { нормами классической латыни и } \\
\text { христианской латыни }\end{array}$ \\
\hline IX-XI вв. & $\begin{array}{l}\text { Начало функ- } \\
\text { циональной } \\
\text { дифферениа- } \\
\text { ции галлоро- } \\
\text { манских и гер- } \\
\text { манских форм } \\
\text { речи. Первые } \\
\text { памятники } \\
\text { французского } \\
\text { языка }\end{array}$ & $\begin{array}{l}\text { Переход к } \\
\text { устойчивой ди- } \\
\text { глоссной ситуа- } \\
\text { ции между гал- } \\
\text { лороманскими } \\
\text { и германскими } \\
\text { формами речи. }\end{array}$ & $\begin{array}{l}\text { 1.Полиномичный латинский язык } \\
\text { с альтернативными эволютивны- } \\
\text { ми нормами классической латыни } \\
\text { и христианской латыни. 2.Полино- } \\
\text { мичный французский язык с эво- } \\
\text { лютивными языковыми нормами } \\
\text { в его территориальных вариантах } \\
\text { (скрипты). } \\
\text { 3. Полиномичный голландский } \\
\text { язык с эволютивными языковыми } \\
\text { нормами в его территориальных } \\
\text { вариантах. }\end{array}$ \\
\hline XII-XV вв. & $\begin{array}{l}\text { Функциональ- } \\
\text { ное закрепле- } \\
\text { ние галлоро- } \\
\text { манских форм } \\
\text { речи в гало- } \\
\text { романской } \\
\text { части Бельгии } \\
\text { и германских } \\
\text { форм речи в } \\
\text { голландской } \\
\text { части }\end{array}$ & $\begin{array}{l}\text { Переход от ро- } \\
\text { манского много- } \\
\text { язычия (фран- } \\
\text { ко-валлонско- } \\
\text { испанского) к } \\
\text { франко-валлон- } \\
\text { ской диглоссной } \\
\text { ситуации }\end{array}$ & $\begin{array}{l}\text { 1.Полиномичный латинский язык } \\
\text { с альтернативными эволютивными } \\
\text { нормами классической латыни и хри- } \\
\text { стианской латыни. 2.Полиномичный } \\
\text { французский язык с эволютивными } \\
\text { языковыми нормами в его территори- } \\
\text { альных вариантах (скрипты). } \\
\text { 3. Полиномичный голландский } \\
\text { язык с эволютивными языковыми } \\
\text { нормами в его территориальных } \\
\text { вариантах (скриптах). }\end{array}$ \\
\hline XVI век & $\begin{array}{l}\text { Начало грам- } \\
\text { матизации и } \\
\text { нормализации } \\
\text { французского } \\
\text { языка }\end{array}$ & $\begin{array}{l}\text { Переход к фран- } \\
\text { ко-валлонской } \\
\text { диглоссной си- } \\
\text { туации }\end{array}$ & $\begin{array}{l}\text { Эволютивный характер разраба- } \\
\text { тываемой единой нормы фран- } \\
\text { цузского языка на территории } \\
\text { Валлонии. }\end{array}$ \\
\hline
\end{tabular}


В репрезентации языковой нормы квебекского варианта определяющее значение имеют оппозиции 1) разговорная квебекская языковая форма/ письменная форма языка, импортированная из Франции; 2) разговорная квебекская форма французского языка/ английский язык. Функционирование в XIX в. французского языка в Квебеке в условиях усиливающейся социальной миноризации ее носителей приводит к разрыву взаимосвязи литературной и разговорной форм в квебекском варианте. Квебекский вариант отграничивается от языка-основы Франции, создавая собственные узуальные языковые нормы, которые негативно воспринимаются самими носителями языка, а также англофонами Квебека. Они отражены в подавляющем большинстве лексикографических и грамматических работ квебекских авторов XIX в. В исторической перспективе квебекский вариант французского языка обнаруживает все большую дифференциацию норм устной и письменной речи, с одной стороны, и нормы литературного языка и просторечия, с другой. Анализ процессов нормогенеза и репрезентации языковой нормы в квебекском обществе показывает, что квебекский языковой коллектив начинает с XIX века все больше признавать в качестве объективных две языковые нормы: внутреннюю (квебекскую) и внешнюю (французскую), пользующиеся различным социальным престижем среди говорящих: квебекская языковая форма представлена в лексикографических работах этого времени как просторечная, грубая, искалеченная, испорченная, неправильная. Внешняя французская как превосходная, идеальная, как языковая форма длительной литературной традиции [Разумова, 20146, 2016].

Концентрация интереса социальной группы на отдельные аспекты социального объекта ввиду его важности для социальной группы или ощущаемой лакунароности знаний об этом объекте выступает еще одним неотъемлемым условием для выработки социальных представлений [Rateau, Moliner et al., 2011:478-480].

Для квебекского варианта французского языка важность категоризации своей собственной языковой нормы имела и имеет до настоящего времени идентификационные основания. Преиму- 
щественное использование французского языка в среде сельских жителей и только в ситуациях устного, неформального общения закрепляет его социальную и стилистическую маркированность на территории Канады как народной формы речи. В общественном сознании сначала англичан, а впоследствии и самих франкофонов Квебека французский канадский (français canadien) приобретает отрицательное коннотативное значение «низкий, неполноценный» и постепенно ассоциируется с понятием миноритарного языка. Указанные выше социальные факторы способствуют позиционированию устной формы речи квебекцев как маркера французской идентичности в начавшемся процессе противостояния французской и английской культур в Квебеке. Язык становится мощным фактором их культурной самоидентификации [Разумова, 2014б].

Интерес бельгийского языкового сообщества к языковой норме мотивируется в разные периоды истории различно. Разрабатываемая в XVI веке концепция языковой нормы имеет в Бельгии практическую направленность: с одной стороны, разрабатываемые меры направлены на улучшение качества франиузского язы$\kappa a$ как лучшего языкового образца в ряду всех диалектных форм; с другой - усилия французских и бельгийских грамматистов XVI века направлены на распространение и усвоение населением разрабатываемого качественного узуса. Основным дидактическим средством для достижения этих двух целей выступают в XVI веке педагогические грамматики. Эта практическая направленность отражена в создаваемых здесь 1) грамматиках франиузского языка как иностранного, изучаемого преимущественно во Фландрии, Нидерландах и западной Германии, и 2) грамматиках франиузского языка как родного, изучаемого в Валлонии. Бельгийские педагогические грамматики сыграли в течение XVI-XIX вв. видную роль в распространении ФЯ на германоязычных территориях. В XVII веке продолжается сближение грамматики как искусства правильного пользования языком с риторикой как искусства $x о$ рошо, красиво строить свою речь. Это слияние риторического и грамматического предопределило возможность появления ново- 
го отношения к языку - ценностного, эстетического, а значит - и развития ценностной, эстетической, моральной нормьл, основанной на принципе «что должно делать», конкретным проявлением которого стала в это время идеология пуризма. Позже обе идеологии - практической ценности и корректности входят как нераздельные в конструирование социального представления о языковой норме [Разумова, 2014a].

Из сказанного следует, что языковое представление, как разрабатываемая и разделяемая в рамках социальной группы форма знания, имеет практическую направленность и способствует построению языковой реальности, общей для индивида и социальной группы. Социальные представления о языке, языковой норме позволяют интерпретировать и осмыслять языковые формы, в рамках которых живет индивид и языковая группа. Они передаются от поколения к поколению посредством традиции, системы воспитания и образования, а также социальных форм общения (коммуникации) и связаны, по мнению представителей французской школы социальной психологии, не только с научной, но и с так называемой естественной мьлслью (pensée naturelle) [Jodelet, 2003]. Отличие между естественной и научной (pensée scientifique) формами мысли иллюстрируется С. Московичи при помощи следующей таблицы:

Таблица 2.

\section{Различие между научной и репрезентативной мыслью} по С. Московичи (Moscovici, 1990:558)

\begin{tabular}{|c|c|}
\hline Научное знание & Естественное знание \\
\hline $\begin{array}{l}\text { - оперирует знаками и концептами; } \\
\text { - основано на эмпирической валид- } \\
\text { ности; } \\
\text { - отвечает на вопрос «как?»; } \\
\text { - имеет фиксированную инферен- } \\
\text { цию; } \\
\text { - имеет ограниченное число следова- } \\
\text { ний ментальных операций; } \\
\text { - для него доступно лишь ограни- } \\
\text { ченное количество сетей отношений } \\
\text { (связей с другими системами). }\end{array}$ & $\begin{array}{l}\text { - оперирует образами и символами; } \\
\text { - основано на валидности по консен- } \\
\text { сусу; } \\
\text { - отвечает на вопрос «почему?»; } \\
\text {-имеет возможность выбора инферен- } \\
\text { ции; } \\
\text { - имеет неограниченное число следова- } \\
\text { ний ментальных операций; } \\
\text { - для него доступно неограниченное } \\
\text { количество сетей отношений (связей с } \\
\text { другими системами). }\end{array}$ \\
\hline
\end{tabular}


Основными качествами репрезентативного знания, согласно С. Московичи являются:

1) спонтанньй формализм (formalisme spontané) - опора в процессе коммуникации не только на научные знания, но и на предсуществующие формулы, клише и стереотипы, отсылающие и (или) устанавливающие между говорящими чувство очевидности знания, что позволяет говорящему «не вдаваться в детали», а экономить свои когнитивные усилия;

2) дуальная цุелеустановка (dualisme causal) - в отличие от научного знания, основанного на строгом следовании причины и следствия, естественное знание опирается на отношение симультанности причины и следствия; симультанное указание на ряд социальных ситуаций уже отсылает к возможным связям двух анализируемых событий, указывая тем самым на причинно-следственные отношения между ними;

3) примат вывода (prima de la conclusion) - если в научном знании вывод следует за процессом проверки научной гипотезы, то в рамках естественного знания гипотеза воспринимается как вывод, что позволяет трансформировать гипотезу в аргумент, истинностное суждение; таким образом, социальный актор, оперирующий естественными знаниями, может использовать (и нередко использует) гипотезу как постулат, имеющий неопровержимую силу;

4) использование приниипа аналогии, что позволяет актору сближать в рамках одного анализа разные и, подчас, разнородные предметы и ситуации действительности, конструируя на их основе различные категории [Moscovici, 1990].

Следует указать, что если научное знание отвергает понятие очевидности и оперирует абстрактными схемами и знаниями, то естественная мысль связывает вещь и слово, наполняя последнее более конкретным содержанием. В результате такой «конкретизации» мысль более не воспринимаются как исключительный продукт интеллектуальной деятельности отдельных людей, а видится как отражение некоего внешнего объекта и, как уже отмечалось, может представлять интерес для большого количества говорящих. Подчеркнем, что именно эту логику опоры, как на научные, так и на естественные знания в процессе конструирования самых разно- 
образных языковых представлений (в том числе, и о языковой норме, собственном и чужом языке, необходимости реформирования их норм, письменности, терминологических систем и пр.) встречаем в рассуждениях о современных национальных языках. Они же и способствовали нередко существенной социальной вовлеченности говорящих в социальные языковые дискуссии, а также существенным изменениям, произошедшим в области национальных языковых политик многих государств на постсоветском пространстве.

Социальные представления интегрируют разнообразнейшие когнитивные структуры: прототипы (определяемые в социальной психологии как идеальная модель), эталоны и типы (концентрирующие в себе значение определенной категории), сценарии (когнитивные структуры, описывающие нормальную последовательность событий), стереотипы (выступают как «обобщенные схемы восприятия» и хранения знаний, своеобразные усеченные концепты, участвующие в процессах категоризации определенного социального объекта) [Moliner, Guimelli, 2015]. Эти когнитивные структуры используются говорящими в процессе категоризации языкового знания, которое обладает достаточно высоким формализмом, клишированностью, стереотипизированностью и, следовательно, возможностью широкого воспроизводства говорящими. Отметим, что социопсихологическое понятие прототипа является аналогом философского и лингвистического понятия нормы, которая выступает, таким образом, в качестве измерительного, оценочного инструмента человеческого опыта. Удобство использования в когнитивной деятельности, в частности, в конструировании языковых представлений усеченных концептов определяется принципом экономии: они предлагают социальному субъекту уже сконструированное, готовое знание-репрезентацию, своеобразную «семантическую заготовку».

\section{Выводы}

Социальные представления предлагают многочисленные способы интерпретации реальности. При этом наличие (явное или только ощущаемое) в их структуре причинно-следственных связей, соединенными с определенными стереотипами придает им известную стабильность. 
Как инструмент интерпретации действительности социальное представление очерчивает в целом верно отделенные аспекты реальных событий и предметов. Однако соединение в нем объективных и субъективных компонентов знания приводят к тому, что данная интерпретация никогда не бывает нейтральной. Об этом можно судить по тем многочисленным отрицательным оценкам, которые латеральные языковые варианте французского языка получали в исторической перспективе в среде говорящих.

Исследование репрезентации языковой нормы квебекского и бельгийского вариантов французского языка показывает, что, будучи формой социальной репрезентации, языковая репрезентация разрабатывается как отношение между социальной группой, социальным объектом и социальным Другим, то есть в терминах социолингвистики - в процессе социокультурного и языкового контактирования социальных групп и складывающихся диглоссных и полилингвальных ситуаций [Разумова, 2014, 2016].

Языковая норма, как один из многичисленных видов социальных представлений предстает как сложный когнитивно-оценочный инструмент, участвующий в процессе категоризации и оценки языка; она позволяет определить его сущностные характеристики: временные и пространственные границы, ценностные компоненты. Понятие языковой нормы используется для их группировки, отбора, установления связи между ними. В этом заключается инструментальный, деятельностный характер языковой нормы. Соединение в рамках языковой нормы рационального и оценочного, социального и индивидуального планов, прескриптивных и дескриптивных элементов свидетельствует о ее сложности и полиморфности как объекте исследования.

\section{Список литературы}

1. Разумова Л.В. Языковая ситуация в Бельгии в исторической перспективе. Чита: Изд-во ЗабГУ, 2014. 221 с.

2. Разумова Л.В. Репрезентация языковой нормы квебекского варианта французского языка: монография. Чита: Изд-во ЗабГУ, 2014. 208 с.

3. Разумова Л.В. Репрезентация языковой нормы в вариантах французского языка за пределами Франции (квебекский и бельгийский 
варианты). Автореф дисс. ...д-ра филол наук. М.: Московский педагогический государственный университет, 2016. 43 с.

4. Рубинштейн Л.С. Основы общей психологии. СПб: Питер, 2002.720 с.

5. Солсо Р. Когнитивная психология. СПб: Питер, 2002. 592 с.

6. Тагард П. Междисциплинарность: торговые зоны в когнитивной науке. // Логос. №1, 2014. С. 35-60.

7. Фаликман М. Когнитивная наука: основоположения и перспективы // Логос. №1., 2014. С. 1-18.

8. Doise W. Les représentations sociales // Traité de psychologie cognitive. P.: Dunod, 1990. Pp. 111-176.

9. Jodelet D. Représentations sociales et mondes de vie. P.: Editions des Archives, 2015. 205 p.

10. Lakoff G. Woman, Fire and dangerous Things: What Categories Reveal about the Mind. Chicago: University of Chicago Press, 1990. 614 p.

11. Moliner P., Guimelli C. Les représentations sociales. Grenoble: Presses huniversitaires de Grenoble, 2015. 144 p.

12. Moscovici S. Psychologie sociale. P.: PUF, 1990. 640 p.

13. Rateau P., Moliner P., Guimelli C., Abric J.C. Social Representation Theory // Handbook of Theories of Social Psychology. London, Thousand Oaks, CA: Sage, 2011. Pp. 478-498.

\section{References}

1. Razumova L.V. Yazykovaya situatsiya v Bel'gii $v$ istoricheskoy perspektive [The language situation in Belgium in a historical perspective]. Chita: ZabGU Publishing House, 2014. 221 p.

2. Razumova L.V. Reprezentatsiya yazykovoy normy kvebekskogo varianta frantsuzskogo yazyka [Representation of the linguistic norm of the Quebec variant of the French language]: monograph. Chita: ZabGU Publishing House, 2014. 208 p.

3. Razumova L.V. Reprezentatsiya yazykovoy normy $v$ variantakh frantsuzskogo yazyka za predelami Frantsii (kvebekskiy i bel'giyskiy varianty) [Representation of the linguistic norm in French variants outside France (Quebec and Belgian variants)]. Abstract. Moscow: Moscow State Pedagogical University, 2016. 43 p. 
4. Rubinstein L.S. Osnovy obshchey psikhologii [Fundamentals of General Psychology]. SPb: Peter, 2002. 720 p.

5. Solso R. Kognitivnaya psikhologiya [Cognitive psychology]. SPb: Peter, 2002. 592 p.

6. Tagard P. Mezhdistsiplinarnost': torgovye zony v kognitivnoy nauke [Interdisciplinarity: Trade Areas in Cognitive Science]. Logos. No. 1, 2014. P. 35-60.

7. Falikman M. Kognitivnaya nauka: osnovopolozheniya i perspektivy [Cognitive Science: Foundations and Perspectives]. Logos. No. 1, 2014. P. 1-18.

8. Doise W. Les représentations sociales. Traité de psychologie cognitive. P.: Dunod, 1990. Pp. 111-176.

9. Jodelet D. Représentations sociales et mondes de vie. P.: Editions des Archives, 2015. 205 p.

10. Lakoff G. Woman, Fire and dangerous Things: What Categories Reveal about the Mind. Chicago: University of Chicago Press, 1990. 614 p.

11. Moliner P., Guimelli C. Les représentations sociales. Grenoble: Presses huniversitaires de Grenoble, 2015. 144 p.

12. Moscovici S. Psychologie sociale. P.: PUF, 1990. 640 p.

13. Rateau P., Moliner P., Guimelli C., Abric J.C. Social Representation Theory. Handbook of Theories of Social Psychology. London, Thousand Oaks, CA: Sage, 2011. Pp. 478-498.

\section{ДАННЫЕ ОБ АВТОРЕ}

Разумова Лина Васильевна, профессор, д. филол. наук, доцент Московский городской педагогический университет 2-ой Сельскохозяйственный проезд, 4, Москва, 129226, Российская Федерачия

lina.razumova@mail.ru

\section{DATA ABOUT THE AUTHOR}

Razumova Lina Vasilyevna, Professor, Doctor of Philology, Docent Moscow City University

4, Vtoroy Selskohoziajstvenny proezd, Moscow, 129226, Russian Federation

lina.razumova@mail.ru

SPIN-code:1727-6755

ORCID: 0000-0001-5225-0413 